\title{
ACUTE NECROTISING RHEUMATIC ARTERITIS IN A CHILD
}

\author{
BY \\ A. T. SANDISON \\ From the Department of Pathology, the University, and Royal Hospital for Sick Children, Glasgon.
}

(RECEIVED FOR PUBLICATION APRIL 13, 1956)

It has for some time been known that acute rheumatism does not affect only the heart but may produce lesions elsewhere in the cardiovascular system as well as in the joints, subcutaneous tissues and central nervous system. In the aorta, the disease process usually begins in the adventitia and only rarely extends beyond the outer third of the media. In the case to be described there was marked change in the intima, not only of the aorta but of the pulmonary arteries.

\section{Case Report}

The patient, a boy aged 7, was admitted to the wards of Dr. J. H. Hutchison at the Royal Hospital for Sick Children, Glasgow. The history was that of normal birth, infancy and early childhood. Tonsillectomy had, however, been done at the age of 5 , because of recurring attacks of tonsillitis. Thereafter the child had remained well until about one year before death. He then began to show loss of appetite, increasing pallor and occasional bouts of fever. He was seen by the family doctor who noticed a heart murmur. On admission he was a pale, poorly nourished boy with a pulse rate of 160 per minute. Systolic and diastolic murmurs were heard at all areas. Blood culture on three occasions was sterile. The E.S.R. was 54 per hour and the tuberculin reaction negative. Despite intensive therapy death occurred suddenly.

Necropsy. The body was that of a poorly nourished boy of body length $1 \cdot 2$ metres. Subcutaneous nodules were palpable over the right elbow posteriorly, over the occiput and the dorsal spine. There was no other external evidence of disease. Dissection showed no significant abnormality of the peritoneum, gastrointestinal tract, gall-bladder, pancreas, adrenals, kidney, ureters, bladder, prostate and testes. The liver $(1,000 \mathrm{~g}$.) and spleen (100 g.) were markedly congested. The cranial cavity, meninges, brain $(1,380$ g.), pituitary, thyroid and thymus glands showed no features of note. There were recent tenuous adhesions between the parietal pericardium and visceral pleura but no pleurisy or pleural effusions. The lungs (each $280 \mathrm{~g}$.) showed only a few small scattered haemorrhagic areas deep in the substance of both upper lobes.
The pericardial cavity was completely obliterated by oedematous fibrous adhesions. The heart weighed $325 \mathrm{~g}$. and was much enlarged in the transverse diameter. The right auricle and ventricle were hypertrophied and dilated with relative incompetence of the tricuspid valve. The pulmonary valve appeared normal. The left ventricle appeared normal but the left auricle was somewhat dilated. There was neither stenosis nor obvious incompetence of mitral and aortic valves. Both of these, however, showed some oedema of the cusps and along the lines of contact of the cusps of both valves were numerous tiny translucent typical rheumatic vegetations. There was moderate subendocardial thickening of the left auricle but no macroscopic change in the great vessels or coronary artery orifices.

Histological Examination. There was evidence of mild respiratory infection with foci of collapse in the lungs which showed neither hyaline membrane nor abundant haemosiderin-containing macrophages. The gastrointestinal tract, pancreas, salivary glands, adrenals, kidneys, lymph nodes, cerebral cortex, medulla oblongata, thyroid, pituitary, testes, prostate, breasts and sympathetic ganglia showed no significant abnormality of parenchyma or of blood vessels. The liver and spleen showed congestion only.

Well formed Aschoff bodies were seen in the endocardium of the left auricular appendage, left auricle and left ventricle (Fig. 1). There were also diffuse inflammatory infiltrates which included some polymorphs. An organizing pericarditis was also noted. Scanty, illformed Aschoff bodies were noted in the myocardium of the right auricle only. There were no endocardial Aschoff bodies in any chamber on the right side but an organizing pericarditis was again evident. The aortic valve cusps were thickened and the presence of organizing surface vegetations was confirmed. The mitral valve cusps were also thickened, a little fibrosed and vascularized and showed surface vegetations (Fig. 2). Aschoff bodies were very numerous in McCallum's area.

Blood Vessels. Longitudinal section through the aorta showed that just distal to the left coronary ostium there was obvious intimal thickening with an infiltrate of lymphocytes and larger darkly-staining histiocytic cells. On section a little distal to this the adventitial coat was oedematous with congestion of the small nutrient vessels. 


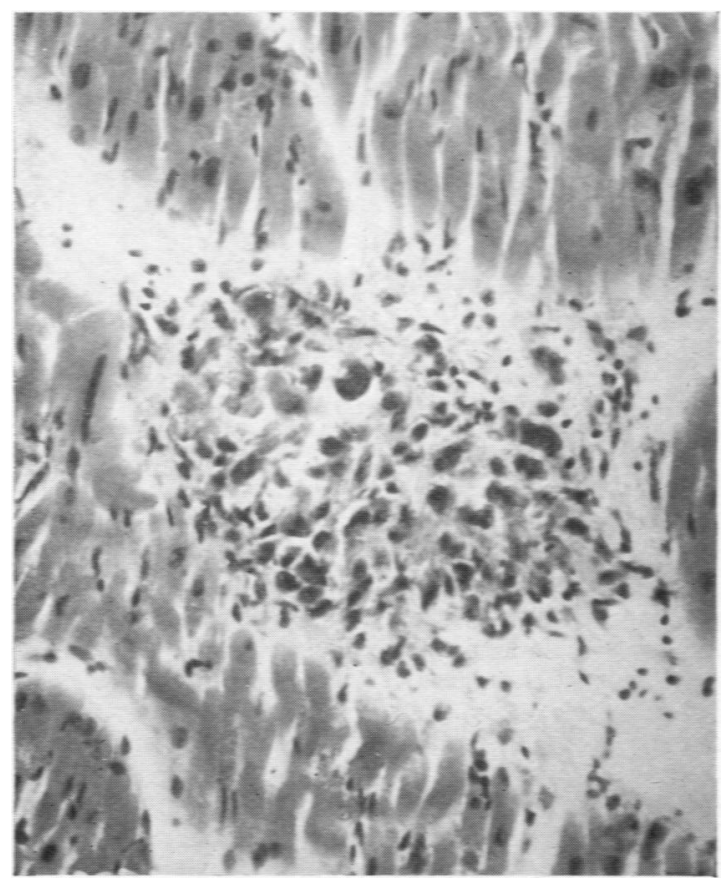

Fig. 1.-An Aschoff body is seen in the connective tissue of the myocardium of the left ventricle. Haemalum and eosin $\times 280$

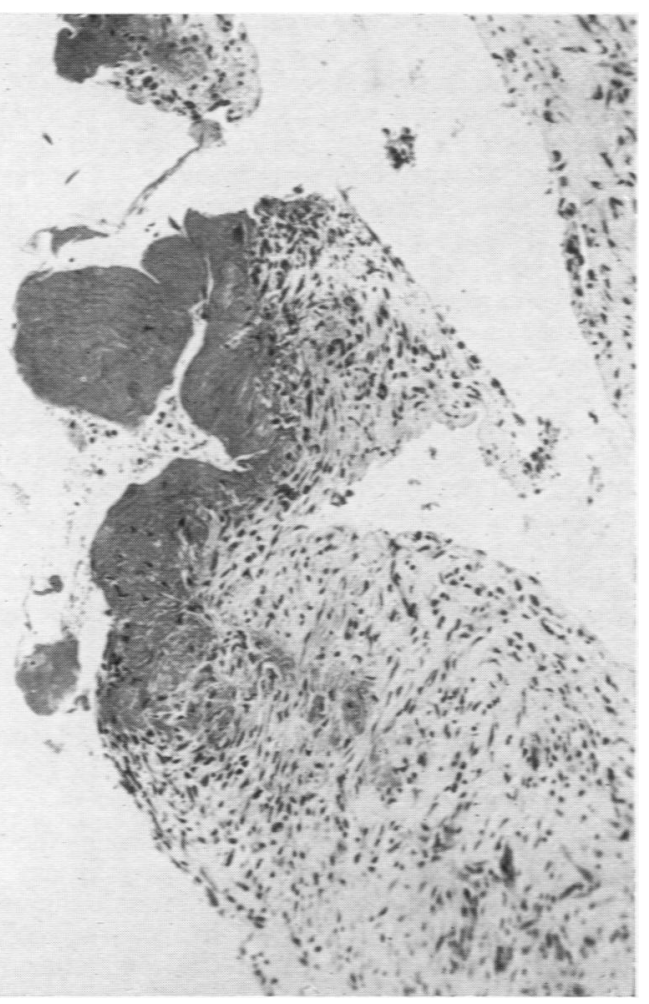

Fig. 2.-Mitral valve cusp showing thickening and increased cellularity with vegetation. $H$. and $E$. $\times 110$.

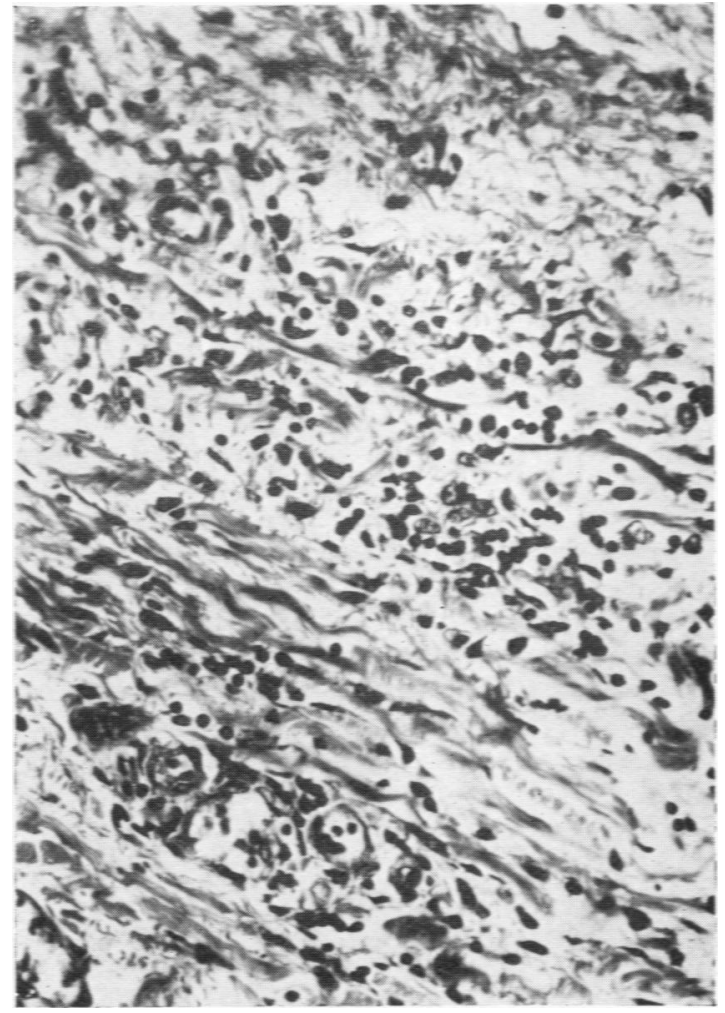

FIG. 3. - In the adventitial coat of the thoracic aorta there is a marked infiltration by mononuclear cellk. Masson. $\times 280$.

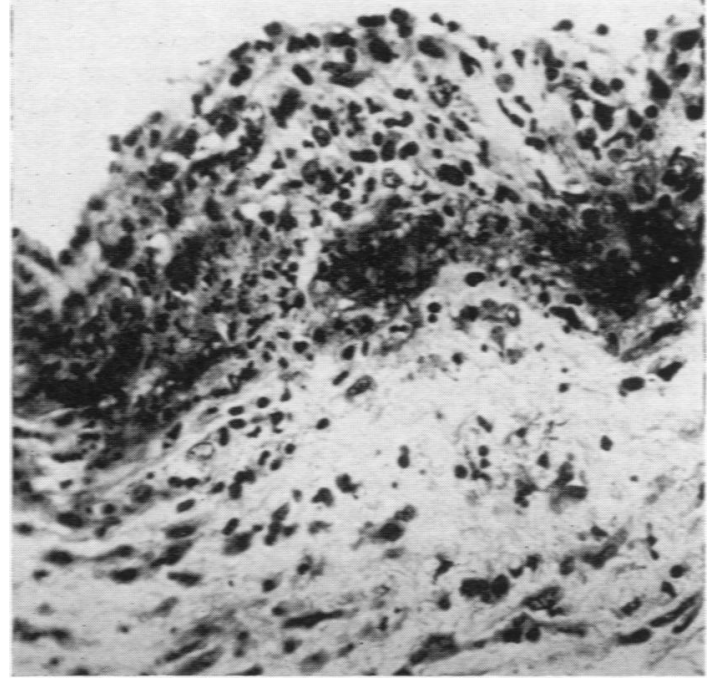

Fig. 4. - The intima of the thoracic sorta shows very severe fibrinoid necrosis of the internal elastic lamina with a large number of polymorphs in the subendothelial tissue. Masson. $\times 280$. 


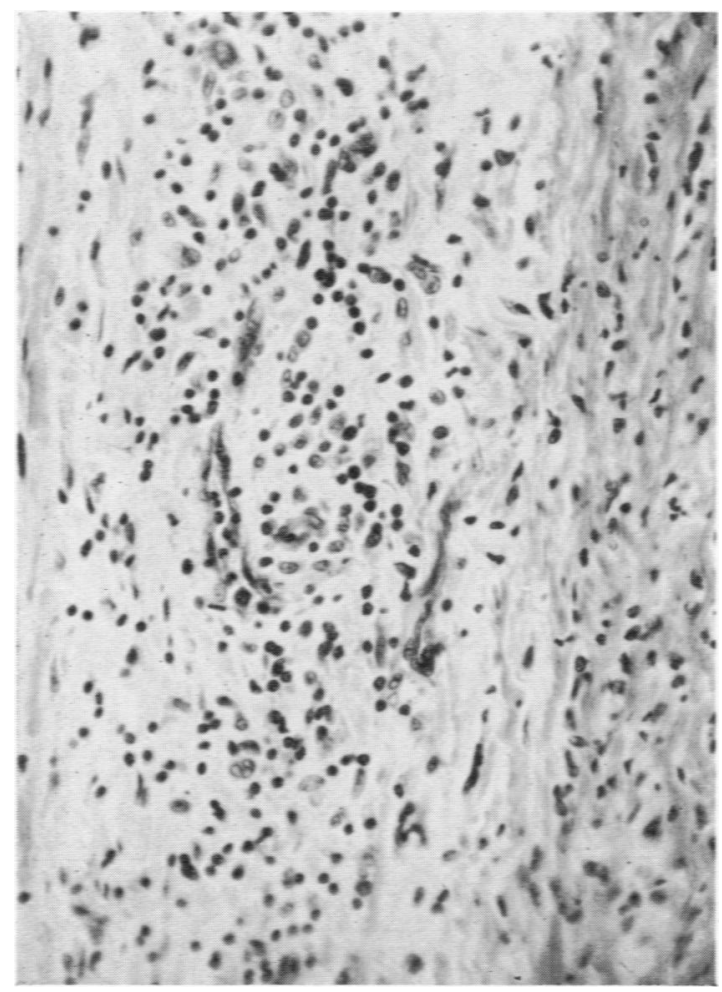

Fig. 5.- The adventitial coat of the abdominal aorta shows a wellestablished infiltrate of lymphocytes and histiocytes around the vasa vasorum. H. and $E$. $\times \mathbf{2 8 0}$.

Around these, but also scattered diffusely throughout was a cellular infiltrate consisting of lymphocytes, scanty plasma cells and eosinophil polymorphs as well as occasional darkly-staining histiocytic cells (Fig. 3). The media showed only slight oedema while the intima was somewhat thickened and pale-staining, with nuclei of rather stellate appearance.

Further distal still, the medial coat again showed some oedema. The intima was markedly affected in a sector representing about one twelfth of the circumference and placed laterally. The maximum increase in thickness of the intima here represented one-half the thickness of the media at this point. Much of the increase in thickness was due to collagen fibres with fibroblastic nuclei. The most striking feature, however, was the great destruction of the internal elastic lamina. This showed increasing fragmentation towards the centre of the lesion, the dull fuchsinophil crimson-red staining appearance contrasting with the bluish-pink of the unaffected elastic tissue of the media as shown by Masson's stain (Fig. 4). Towards one end of the affected section there was a short length where the immediately subintimal elastic tissue showed a similar fibrinoid change. There was a well-established polymorph infiltrate most highly developed where the fibrinoid

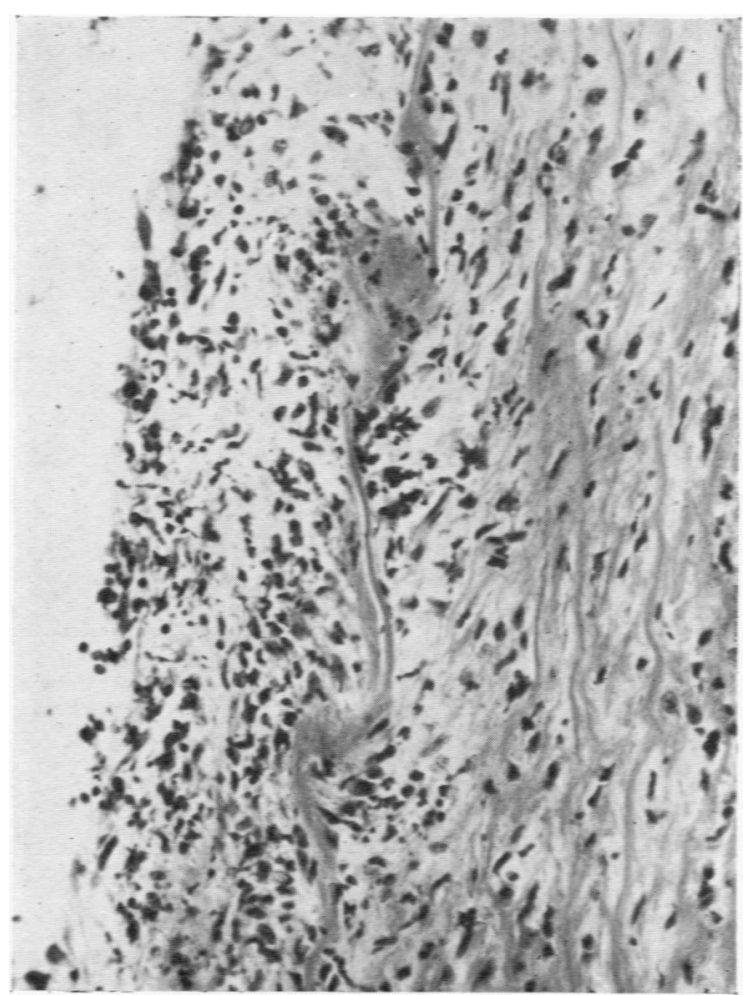

FK. 6.-There is a thickening and fibrinoid change of the internal elastic lamina of the abdominal aorta. The intima is infiltrated by polymorphs, many of degenerate appearance. The endothelium has been lifted and in some places has disappeared. H. and E. $\times 280$.

appearance was present. Over the affected portion the endothelium was rather lifted, possibly due to the infiltration of inflammatory cells.

Abdominal Aorta. Section at several different levels showed in the adventitial coat perivascular round cell infiltrates, mainly lymphocytic but with occasional plasma cells and histiocytes (Fig. 5). The medial coat showed some oedema with occasional scanty lymphocytes and histiocytes around the vasa vasorum. The appearances in the intima varied from simple thickening of the layer. which was pale-stained and showed some lymphocytic infiltration, to one of profound structural alteration. The latter appearances resembled closely those described above in the thoracic aorta. The affection was again sectoral but occupied about one-quarter of the circumference of the lumen. The intima was thickened, pale and consisted of two layers of collagen. Towards the media the fibres were well-formed and the cells fibrocytic in character but towards the lumen they were finer, immature and associated with fibroblastic cells. Between these distinct layers a well-formed elastic lamina distinct from the definitive internal lamina showed fibrinoid change and was surrounded by polymorphs which were also present in lesser number in the 


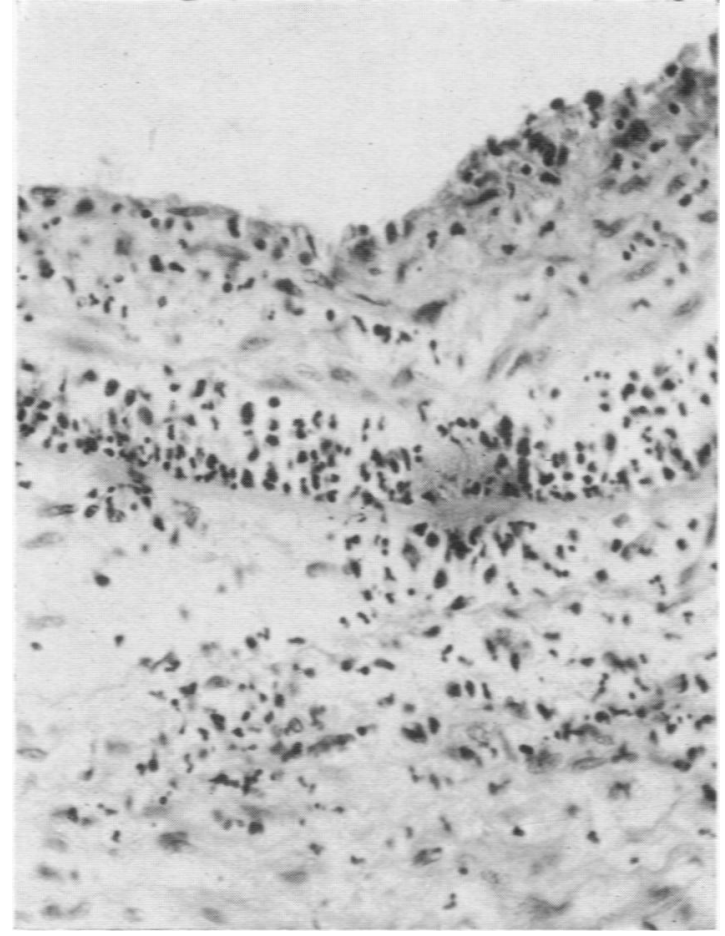

Fig. 7.-A major branch of the pulmonary artery showing less severe arteritis. An early polymorph infiltrate extends into the intima. H. and $E$. $\times 280$.

intima towards the lumen (Fig. 6). This fibrinoid change was not of equal severity along the entire length of the recently formed elastic lamina. The endothelium was again raised by the inflammatory infiltrate.

Subclavian Artery. The adventitia showed some simple round cell infiltration; the media slight oedema, while the intima was pale and a little thickened. In the major branches of the subclavian artery occasional lymphocytes and histiocytes were seen in the adventitia but no other abnormality was noted.

Coronary Arteries. There were no significant changes in the major vessels.

Pulmonary Arteries. The major arteries showed well marked aggregates of round cells in the adventitia, mainly around the vasa vasorum. Also present were occasional plasma cells, some binucleate. Scanty round cells were also seen in the media around the vasa. Also present in the media were occasional polymorphs scattered throughout the outer aspects of the coat. These were present only in that sector of the artery in which the intima was affected. This intimal change consisted of severe damage to the internal elastic lamina, which was thickened and granular with very numerous polymorphs present on that side adjacent to the lumen with fewer on the medial side. Many of the polymorphs

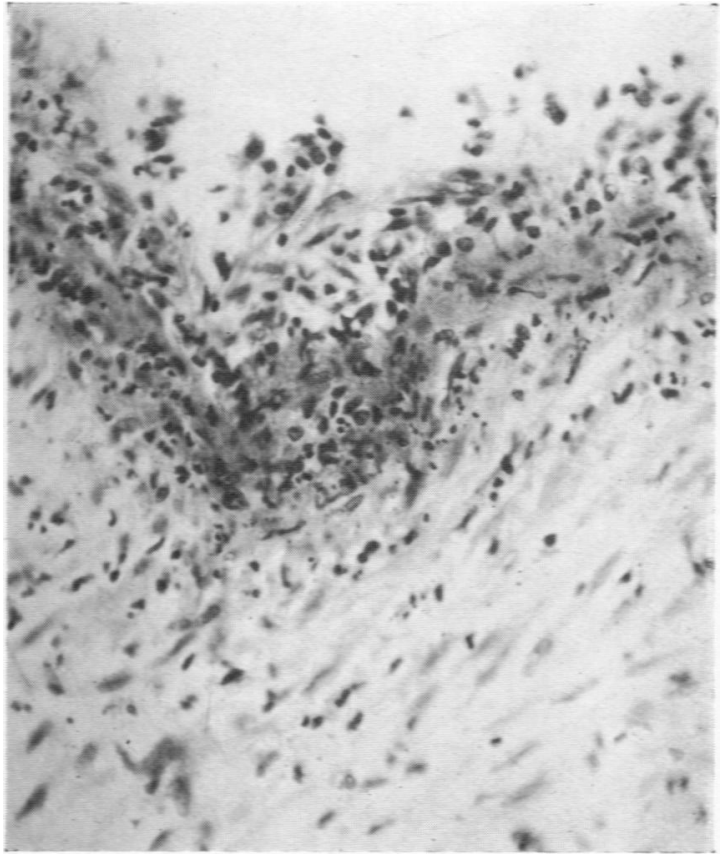

Fig. 8.-A major branch of the pulmonary artery closely adjacent to that seen in Fig. 7. The fibrinoid change in the internal elastic lamina is quite severe and the inflammatory reaction is well marked. H. and $E$. $\times 280$.

appeared quite degenerate (Figs. 7 and 8). In the lung substance the major branches only of the pulmonary artery were also affected. Here again the internal elastic lamina showed an appearance of fibrinoid necrosis with numerous polymorphs associated with the damaged tissue. In the adventitia round cell infiltrates were noted surrounding the vasa.

Superior Vena Cava. This showed scanty round cells in the adventitia coat around the vasa with perhaps slight thickening of the intima.

Inferior Vena Cava. In the thoracic portion this showed scanty lymphocytes and histiocytes in the adventitia with slight thickening of the intima also. In the abdominal portion slight intimal thickening was the only abnormality.

Pulmonary Veins. Apart from scanty round cell infiltrates in the adventitia no abnormality was seen. The pulmonary veins in the substance of the lung showed no abnormality.

Coronary Vein. One small coronary vein showed a sectoral change with an infiltrate of polymorphs and plasma cells in the subintimal zone.

\section{Discussion}

The effects of acute rheumatism on the walls of arteries are briefly described in most standard text- 
books, e.g., Cappell (1951). Such lesions, although most often found in the aorta, may also occur in smaller vessels. In the aorta the lesions are said to begin in the adventitia and consist of infiltration by lymphocytes and plasma cells. Here and there foci may be noted where there is a marked histiocytic reaction and typical Aschoff bodies may form. This cellular infiltration sometimes spreads to the media and may lead to absorption of elastic tissue but rarely extends further than the outer third of the medial coat. Of other vessels affected, the lesions are most often found in the smaller visceral arteries. They are of more acute character and may show some medial necrosis with leucocytic infiltration, somewhat resembling the lesions of polyarteritis nodosa although thrombosis and aneurysmal dilatation have not been observed.

Attention was first drawn to the occurrence of rheumatic aortitis by Pappenheimer and von Glahn (1924, 1926, 1927). In their first paper they drew attention to Aschoff bodies or cells in the aortic adventitia; in the second to affection of the media, where amphophilic cells were present along with polymorphs and round cells; and, in the third, differentiated rheumatic aortitis into two types, one with a perivascular reaction and another with diffuse reaction in the intima and subjacent media. Gray and Aitken (1929) described four cases where there was no evidence of syphilis or arteriosclerosis but a history of rheumatic fever, chorea or tonsillitis and in which there were old lesions of media and intima.

Kugel and Epstein (1928) studied 24 cases of active rheumatism and showed that in 17 instances Aschoff bodies or more often diffuse infiltrates containing large cells were present at the musculoarterial junctions of the pulmonary arteries. In two cases there were macroscopic lesions of the intima of the pulmonary arteries, while in five there was histological evidence of intimal affection. In one instance there was actual fibro-elastic necrosis with an inflammatory infiltrate. The medial wall showed cellular infiltrates in five cases and the vasa vasorum were sometimes thickened. In 22 cases the aorta was also examined and Aschoff bodies were never found in the wall. Paul $(1927,1928)$, in reviews of pleural and pulmonary lesions in rheumatic fever, stated that while Aschoff bodies may be found in the main pulmonary arteries, the lesions in the moderately sized vessels are less specific while in the arterioles there may be a fairly marked periarteritis. Chiari (1930) also described lesions of the pulmonary arteries. Epstein and Greenspan (1941) detailed the appearances of the lung in so-called rheumatic pneumonia and conclude that there is a characteristic but not specific pulmonary picture. They describe arteritis of the pulmonary arteries in four out of 45 cases. These four occurred where death intervened at a second or later attack of acute rheumatism.

Von Glahn and Pappenheimer (1926) described inflammatory changes of exudative type in the peripheral vessels in rheumatism. Karsner and Bayless (1934) reviewed the literature of vascular changes in acute rheumatism including those in the aorta and pulmonary artery. They analysed carefully the appearances of the coronary arteries in 56 cases where the heart showed unequivocal Aschoff bodies and established the great frequency of affection of the coronary arteries in acute rheumatism as witnessed by fibrinoid change, necrosis, alteration in the elastic tissue, etc. Gross, Kugel and Epstein (1935) have also studied the coronary arteries in cases of acute and 'healed' rheumatic heart disease and concluded that some coronary lesions are so peculiar as to suggest the possibility of a specific rheumatic nature. Klinge (1930 and 1933) has also described in detail vascular change in peripheral vessels. Anderson (1953) summarized the appearances seen in the peripheral vessels. These lesions are not confined to the coronary arteries but may be seen in the lungs, pancreas, kidney, ovary, testis and skin. Histologically the entire thickness of the wall is affected and frequently the whole circumference. The endothelium is swollen, the media thickened by oedema and fibrinoid change, with damage to the internal elastic lamina. Not infrequently large arterioles show an exudative and necrotizing panarteritis. Musculo-elastic hyperplasia may greatly narrow the vessel lumen.

Shaw (1929) investigated the topography of lesions in rheumatic fever and stated that aortitis is most often seen in the proximal and not in the abdominal aorta. He further stated that while the pulmonary artery and its major branches may be affected, lesions are not seen in the intrapulmonary branches. Less specific lesions are described in the carotid, subclavian and renal arteries and in the superior vena cava.

Lendrum (1955) has recently discussed the changes in the pulmonary arteries in mitral stenosis and considers these to be an example of fibrinous vasculosis. This term, 'fibrinous vasculosis', is proposed for the essentially similar microscopic appearances in a group of disparate conditions which include infarction, malignant hypertension, polyarteritis nodosa, disseminated lupus erythematosus, dermatomyositis and thrombotic thrombocytopenia. He points out that in all the above- 
mentioned conditions the fibrin is quite often seen under an intact endothelium; the change may be segmental or affect the entire circumference. The three forms of fibrinous vasculosis may be histologically indistinguishable, except so far as vessels of different calibre are involved in the different diseases. The concept of a fibrinous vasculosis as a form of exudation common to all diseases mentioned, depending on an upset between the pressure in the vessel and the permeability of the lining may, he thinks, help in our understanding of the peculiar diseases in which it occurs. Lendrum has seen in the lungs fibrinous vasculosis in cases of mitral stenosis, of primary pulmonary hypertension, of disseminated lupus erythematosus, of drug-induced arteritis and of infarction in a case of acute rheumatic disease. The lungs from the cases of mitral stenosis showed a more widespread and severe involvement of the vessels than was seen in any other condition. Lendrum believes that in cases with mitral valve stenosis it can be reasonably assumed that a state of pulmonary hypertension existed during life and that in such cases the fibrinous vasculosis can be related to hypertension, it being unnecessary to postulate a state of hyperergy.

In the present case it is probable that the earliest changes occurred in the adventitia since the disease process is limited to this layer in some of the vessels examined. Possibly in many instances the condition does not progress further but in others extends to the outer third of the media. The media was nowhere strikingly affected in the case described above but intimal changes were severe both in the aorta and larger pulmonary arteries, being similar to those described in peripheral vessels. Although Aschoff bodies were frequently seen in the heart they were invariably absent from the blood vessel lesions. The involvement of the abdominal portion of the aorta is contrary to the experience of Shaw (1929).
The lesions described above appear to be essentially of an acute necrotizing type similar to those seen in polyarteritis and related diseases. In the present case there was no established mitral stenosis and the condition is not the fibrinous vasculosis complicating pulmonary hypertension as described by Lendrum. In any case the involvement of the systemic blood vessels precludes this explanation. The condition almost certainly represents an aspect of the acute rheumatic process. The major changes are seen only in the arteries although the adventitia of the veins are also mildly affected.

\section{Summary}

Acute necrotizing arteritis is described in a 7-year-old boy who died of acute rheumatism. Both aorta and pulmonary artery showed severe changes. The condition is almost certainly part of the rheumatic process.

My thanks are due to Dr. J. H. Hutchison for permission to publish this case and Mr. W. Mason for technical assistance and for the photographs.

\section{REFERENCES}

Anderson, W. A. D. (1953). Pathology, 2nd ed. London.

Cappell, D. F. (1951). Muir's Textbook of Pathology, 6th ed. London.

Chiari, H. (1930). Klin. Wschr., 9, 1862.

Epstein, E. Z. and Greenspan, E. B. (1941). Arch. intern. Med. 68, 1074 .

Gray, S. H. and Aitken, L. (1929). Arch. Path. (Chicago), 8, 451

Gross, L, Kugel, M. A. and Epstein, E. Z. (1935). Amer. J. Path. 11, 253.

Karsner, H, T. and Bayless, F. (1934). Amer. Heart. J., 9, 557

Klinge, F. (1930). Virchows Arch. path. Anat. 278, 438.

(1933). Ergebn. allg. Path. path. Anat., $27,53$.

Kugel, M. A. and Epstein, E. Z. (1928). Arch. Path., (Chicago), 6. 247.

Lendrum, A. C. (1955). Pubmonary Circulation and Respiratory Diseases: A Symposium. Dundee.

Pappenheimer, A. M. and Von Glahn, W. C. (1924). J. med. Res., 4, 489.

(1926). Amer. J. Path., 2, 15.

Ta (1927). Ibid., 3, 583.

Paul, J. R. (1927). Arch. Path. (Chicago), 3, 354

- (1928). Medicine (Baltimore), 7, 383.

Shaw, A. F. B. (1929). Archives of Disease in Childhood, 4, 155.

Von Glahn, W. C. and Pappenheimer, A. M. (1926). Amer. J. Path. 2. 235 . 